\title{
Proposição para a incorporação da preservação digital nas políticas públicas de informação em saúde
}

\author{
Proposition for the incorporation of digital preservation in public health \\ information policies
}

\section{Propuesta para la incorporación de la preservación digital en las políticas de información de salud pública}

\author{
Gillian Queiroga ${ }^{1, a}$ \\ gillianqueiroga@gmail.com | https://orcid.org/oooo-0003-4736-893X \\ ${ }^{1}$ Universidade Federal da Bahia, Instituto de Ciência da Informação. Salvador, BA, Brasil. \\ a Doutorado em Difusão do Conhecimento pela Universidade Federal da Bahia.
}

\section{RESUMO}

Este artigo possui como objetivo identificar ações governamentais no âmbito dos sistemas e serviços de saúde que visam a adoção de políticas públicas relacionadas à preservação digital em saúde. As políticas públicas de informação e de arquivos são transversais às políticas públicas de saúde e contribuem diretamente para a garantia dos direitos dos cidadãos preconizados pelo Sistema Único de Saúde (SUS). Neste sentido, as políticas de preservação digital são essenciais para garantir o acesso às informações a gerações futuras. A pesquisa caracteriza-se como aplicada e exploratória. Utiliza como amostra os textos completos da Consolidação das Normas Infralegais do SUS. Os resultados apontam para a necessidade de ações voltadas para a preservação digital em saúde por meio da adoção de políticas públicas. Por fim, destaca-se que a participação popular no desenvolvimento destas políticas públicas de informação em saúde é essencial para a transparência das ações governamentais.

Palavras-chave: Preservação digital; Gestão de documentos; Arquivologia; Sistema Único de Saúde; Políticas de informação; Políticas de arquivo; Informação em saúde. 


\section{ABSTRACT}

This article seeks to identify governmental actions within the scope of health systems and services that aim to adopt public policies related to digital preservation in health. Public information and archive policies are transversal to public health policies and directly contribute to guaranteeing the rights of citizens advocated by the Unified Health System (SUS). In this sense, digital preservation policies are essential to guarantee access to information for future generations. The research is characterized as applied and exploratory. It uses as a sample the complete texts of the Consolidation of Infralegal Norms of SUS. The results point to the need for actions aimed at digital preservation in health through the adoption of public policies. Finally, it is emphasized that popular participation in the development of these public health information policies is essential for the transparency of governmental actions.

Keywords: Digital preservation; Records management; Archival science; Single Health System; Information policies; Archive policies; Health information.

\section{RESUMEN}

Este artículo tiene como objetivo identificar acciones gubernamentales dentro del alcance de los sistemas y servicios de salud que apuntan a adoptar políticas públicas relacionadas con la preservación digital en salud. Las políticas de información pública y archivo son transversales a las políticas de salud pública y contribuyen directamente a garantizar los derechos de los ciudadanos que defiende el Sistema Único de Salud (SUS). En este sentido, las políticas de preservación digital son esenciales para garantizar el acceso a la información para las generaciones futuras. La investigación se caracteriza por ser aplicada y exploratoria. Utiliza como muestra los textos completos de la Consolidación de las Normas Infralegales del SUS. Los resultados apuntan a la necesidad de acciones dirigidas a la preservación digital en salud a través de la adopción de políticas públicas. Finalmente, se enfatiza que la participación popular en el desarrollo de estas políticas de información de salud pública es esencial para la transparencia de las acciones gubernamentales.

Palabras clave: Preservación digital; Gestión de documentos; Archivología; Sistema único de Salud; Políticas de información; Políticas de archivo; Información de salud.

Este artigo compõe o Dossiê Preservação Digital.

Contribuição dos autores: o autor é responsável por todo o trabalho.

Declaração de conflito de interesses: não há.

Fontes de financiamento: apoio do CNPQ por meio do projeto 'Informação, documentos, arquivos e repositórios em saúde: mecanismos de difusão de conhecimentos para as inovações gerenciais nos sistemas de saúde', coordenado pelo Prof. Francisco José Aragão Pedroza Cunha.

Considerações éticas: não há.

Agradecimentos/Contribuições adicionais: não há.

Histórico do artigo: submetido: 04 maio 2020 | aceito: 28 jul. 2020 | publicado: 30 set. 2020.

Apresentação anterior: não houve.

Licença CC BY-NC atribuição não comercial. Com essa licença é permitido acessar, baixar (download), copiar, imprimir, compartilhar, reutilizar e distribuir os artigos, desde que para uso não comercial e com a citação da fonte, conferindo os devidos créditos de autoria e menção à Reciis. Nesses casos, nenhuma permissão é necessária por parte dos autores ou dos editores. 


\section{INTRODUÇÃO}

O objetivo deste artigo é identificar ações governamentais no âmbito dos sistemas e serviços de saúde que visam à adoção de políticas públicas relacionadas à preservação digital em saúde. O uso dos documentos digitais em ambientes organizacionais, além de uma necessidade, é um anseio de grande parte dos gestores que almejam a informatização de seus serviços, e a área de saúde não foge a esta regra. Existe um grande desejo por parte dos profissionais de saúde de utilizar documentos digitais e todas as suas tecnologias de informação associadas. O emprego destas tecnologias não é algo negativo, pelo contrário, traz um grande benefício.

Entretanto, para que tal uso ocorra de forma segura, existe uma série de requisitos arquivísticos que visam garantir não apenas a segurança das informações dos pacientes, mas também que as informações em saúde sejam preservadas adotando-se critérios que garantam a confiabilidade e a autenticidade dos documentos. O Conselho Nacional de Arquivos (Conarq), por exemplo, é um órgão colegiado, vinculado ao Ministério da Justiça e Segurança Pública, que tem por finalidade definir a política nacional de arquivos públicos e privados. É neste sentido que se tornam importantes a adoção das teorias, procedimentos e técnicas arquivísticas por meio dos serviços e sistemas de informação em saúde. Neste processo, evidenciar as práticas arquivísticas por meio das políticas públicas de informação em saúde é essencial para o estabelecimento de premissas que garantam a organização, o tratamento e o armazenamento dos documentos em ambientes digitais.

As políticas públicas de informação e de arquivos são transversais às políticas públicas de saúde e contribuem diretamente para a garantia dos direitos dos cidadãos preconizados pelo Sistema Único de Saúde, tais como: a universalidade, a equidade e a integralidade. Além disso, também contribuem para a garantia dos princípios organizativos da regionalização e hierarquização; descentralização e comando único; e da participação popular. A participação popular no dia a dia dos serviços, e por meio dos Conselhos e Conferências de Saúde, é fundamental para o acompanhamento, avaliação e monitoramento das políticas públicas de saúde do Estado Brasileiro.

Com o intuito de alcançar o objetivo proposto neste artigo, foi realizado um levantamento e análise das ações governamentais voltadas para a preservação digital, com base nas Portarias de Consolidação (PRC) vigentes no âmbito do Ministério da Saúde. Neste sentido, este artigo está estruturado, além desta Introdução, nas seguintes seções: as políticas públicas de informação em saúde; importância das teorias arquivísticas para a garantia da preservação digital em saúde; percurso metodológico; análise dos resultados; e, por fim, as considerações finais.

\section{AS POLÍTICAS PÚBLICAS DE INFORMAÇÃO EM SAÚDE}

A adoção de políticas públicas que garantam o acesso e a segurança das informações é essencial para o desenvolvimento de qualquer sociedade. Uma política pública é, antes de tudo, uma construção social e de pesquisa; social porque parte de uma necessidade comum a determinada sociedade e de pesquisa por esta ser fundamental para a identificação e interpretação de problemas, assim como para a constituição de um quadro de análise da ação pública ${ }^{1}$. Neste contexto, estudar a ação pública é fundamental para "compreender as lógicas implementadas nestas diferentes formas de intervenção sobre a sociedade, em identificar os modos de relação existentes entre atores públicos e privados e em compreender como a ação pública recobre as dinâmicas imprecisas e evolutivas da fronteira entre Estado e sociedade"1.

A adoção de políticas públicas pode ser compreendida como o 'Estado em ação', ou seja, o conjunto de atividades desenvolvidas por um governo de forma direta ou por delegação $0^{2,3,4}$. Vale ressaltar que a existência de textos legais ou reguladores de uma determinada atividade ou setor não são suficientes para 
afirmar que existe uma política pública3,5. Conforme Silva ${ }^{5}$, "o registro de uma lei, regulamento ou norma, impresso e publicado em qualquer meio não tem caráter e o componente dinâmicos de uma política pública. A letra 'morta' da lei possibilita interpretações múltiplas, o que exige, com frequência, mediação. Tende, assim, a se afastar daquilo que se entende por política pública”.

Ainda de acordo com Muller e Surel, "uma política pública é formada, inicialmente, por um conjunto de medidas concretas que constituem a substância "visível" da política. Esta substância pode ser constituída de recursos: financeiros (os créditos atribuídos aos ministérios); intelectuais (a competência que os atores das políticas são capazes de mobilizar); reguladores (o fato de elaborar uma nova regulamentação constitui um recurso novo para os tomadores de decisão); e materiais. Ela é também constituída de 'produtos', isto é, de outputs reguladores (normativos), financeiros, físicos"1. Nesse sentido, pode-se afirmar que as políticas públicas são o conjunto de ações de um estado que se constituem de recursos financeiros, intelectuais, reguladores e materiais ${ }^{1}$.

Franzese $^{2}$, com o intuito de melhor representar a ação governamental, optou pode dividir a proposição de uma política pública em quatro fases, a saber: formação da agenda, formulação, implementação e avaliação. O Quadro 1 apresenta a caracterização de cada uma destas fases.

\section{Quadro 1 - Fases de uma política pública}

\begin{tabular}{|l|l|}
\hline Fase & Características \\
\hline Formação da Agenda & $\begin{array}{l}\text { Constitui o momento inicial da política pública, ou seja, o espaço em que são elencados } \\
\text { os problemas ou assuntos que chamam atenção do governo ou dos cidadãos. }\end{array}$ \\
\hline Formulação & $\begin{array}{l}\text { Corresponde ao momento de elaboração e escolha de alternativas para um determinado } \\
\text { problema que ascendeu à agenda governamental. Não obstante o papel da técnica e da } \\
\text { especialização na formulação de soluções, o processo decisório é povoado por diversos } \\
\text { autores, e o produto será o resultado da interação entre estes. Esta fase envolve } \\
\text { a transformação de dados em informações relevantes, com o objetivo de produzir } \\
\text { conhecimento sobre a ação orientada. }\end{array}$ \\
\hline Implementação & $\begin{array}{l}\text { O momento em que se implantam intenções para obter impactos e consequências. } \\
\text { Apresenta uma complexidade de ações conjuntas com múltiplas normas, perspectivas } \\
\text { diversas e atores cambiáveis, em que a execução das atividades depende da clareza } \\
\text { com que as metas e objetivos são fixados e da consistência com que são comunicados. }\end{array}$ \\
\hline Avaliação & $\begin{array}{l}\text { Fase essencial para que se consiga observar os resultados produzidos pela } \\
\text { implementação da política. Esta fase deve se constituir de um processo sistemático de } \\
\text { análise que permita acompanhar os resultados e impactos da intervenção e orientar } \\
\text { açôes futuras. }\end{array}$ \\
\hline
\end{tabular}

Fonte: Adaptado de Franzese (2011)² e Sousa (2006)

O Brasil, além dos atores governamentais que participam de todo o processo de produção de uma política pública, conta com "um tipo de participação peculiar, que são os mecanismos de democracia participativa, pelos quais os cidadãos podem interferir diretamente na política pública”². Na área da saúde, esta representação se dá por meio da participação de representantes de setores da sociedade nos Conselhos Nacional, Estaduais e Municipais de Saúde (representações do governo, prestadores de serviço, trabalhadores de saúde e usuários) e pela participação nas Conferências de Políticas Públicas que ocorrem a cada quatro anos. Por exemplo, na $8^{\text {a }}$ Conferência Nacional de Saúde, realizada em 1986, após o período de redemocratização, foram apresentadas propostas de mudanças fundamentais na estrutura da política pública de saúde no Brasil, e foi produzida uma série de documentos que esboçaram a criação do Sistema Único de Saúde (SUS)².

A proposta do SUS está vinculada à ideia de que todos possuem direito à saúde. Paim afirma que "com a Constituição da República de 1988, a saúde passou a ser reconhecida como um direito social, ou seja, inerente à condição do cidadão, cabendo ao poder público a obrigação de garanti-lo". Essa "conquista política e social pode ser atribuída a 
diversas lutas e esforços empreendidos pelo movimento da Reforma Sanitária, entre 1976 e 1988. Pela primeira vez na história do Brasil, foi promulgada uma Constituição que reconhece a saúde como direito social, dispondo de uma secção específica e contando com cinco artigos destinados à saúde”.

A Lei n ${ }^{0} 8.080^{8}$, de 19 de setembro de 1990, que dispõe sobre as condições para a promoção, proteção e recuperação da saúde, a organização e o funcionamento dos serviços correspondentes e dá outras providências, regula, em todo o território nacional, as ações e serviços de saúde, executados, isolada ou conjuntamente, em caráter permanente ou eventual, por pessoas naturais ou jurídicas de direito público ou privado. Desta forma, considerando ainda os princípios do SUS, as políticas públicas de informação em saúde são essenciais para um efetivo funcionamento do sistema de saúde brasileiro e contribuem para a garantia do direito de acesso à saúde preconizado pela Constituição Brasileira de $1988^{9}$.

Ainda de acordo com Jardim, um "conjunto de decisões governamentais no campo da informação não resulta necessariamente na constituição de uma política pública de informação". Para que isto ocorra, "é necessário que se defina o universo geográfico, administrativo, econômico, temático, social e informacional a ser contemplado pela política de informação" 5. Jardim complementa tal pensamento ao afirmar que as políticas públicas de informação "são norteadas por um conjunto de valores políticos que atuam como parâmetros balizadores à sua formulação e execução. Podem estar ‘difusas' no âmbito de outras políticas públicas, mas não implícitas. O Estado democrático é, por princípio, incompatível com políticas públicas de saúde, educação, habitação ou informação, que não sejam explícitas”.

Desta forma, entende-se que é uma premissa, em Estados democráticos, que as políticas públicas de informação estejam transversalmente explicitadas por meio dos dispositivos legais em todas as áreas do Estado e sejam acessíveis a toda a população. Um marco importante no que diz respeito à democratização do acesso à informação no Brasil foi a publicação, em 18 de novembro de 2011 , da Lei n. ${ }^{0} 12.5^{2} 7^{10}$, conhecida como a Lei de Acesso à Informação.

Neste trabalho, compreende-se por políticas públicas de informação em saúde o conjunto de ações governamentais que, norteadas por valores políticos, visam ao aperfeiçoamento dos processos relacionados ao uso das informações produzidas, recebidas e/ou acumuladas por meio dos sistemas e serviços de saúde. Uma política pública de informação deve apresentar aspectos como o comprometimento do Estado com o uso das informações públicas e que a sociedade possua condições de acesso e reconheça a importância destas informações ${ }^{5}$.

No contexto das políticas públicas de informação estão as políticas públicas de arquivo. As políticas públicas de arquivo podem ser entendidas como "o conjunto de premissas, decisões e ações - produzidas pelo Estado e inseridas nas agendas governamentais em nome do interesse social - que contemplam os diversos aspectos (administrativo, legal, científico, cultural, tecnológico etc.) relativos à produção, ao uso e à preservação da informação arquivística de natureza pública e privada"11.

Toda política de arquivo é uma política de informação, entretanto, nem toda política de informação é uma política de arquivo. Temos como exemplo as políticas de museu, bibliotecas e de informática. Jardim ${ }^{5}$ ainda destaca a diferença entre legislação arquivística e política arquivística ao afirmar que a "legislação arquivística fornece elementos normalizadores à política arquivística, mas não é em si mesma uma política”. Ressalta, por exemplo, que em alguns casos as políticas arquivísticas e as políticas de governo eletrônico "são concebidas e desenvolvidas como se pertencessem a universos paralelos. Ambas as iniciativas perdem com essa ausência de interfaces, especialmente o campo arquivístico, normalmente menos visível que aquele relacionado com as questões inerentes aos projetos de governo eletrônico".

Nesta perspectiva, é possível supor que existe um distanciamento entre as proposições governamentais relacionadas aos ambientes digitais, a exemplo do governo eletrônico, e as ações voltadas para a garantia da preservação com base nos requisitos arquivísticos. 


\section{IMPORTÂNCIA DAS TEORIAS ARQUIVÍSTICAS PARA A GARANTIA DA PRESERVAÇÃO DIGITAL EM SAÚDE}

O uso das teorias, procedimentos e técnicas arquivísticas é essencial para a melhoria de qualquer serviço organizacional. Com o surgimento dos documentos digitais, a Arquivologia, assim como outras áreas do conhecimento, precisou se adequar por meio da proposição de novas teorias relacionadas à organização, tratamento e arquivamento dos documentos em ambientes digitais. Nesta perspectiva, a partir da década de 1980, surgiram teorias, como por exemplo a Diplomática Contemporânea no Canadá e o Records Continuum na Austrália, preocupadas com uso e preservação dos documentos arquivísticos digitais ${ }^{12,13}$.

Conforme Silva e Flores ${ }^{14}$, no Brasil, "a preocupação na preservação digital, com uma abordagem voltada para o campo da arquivologia, foi fomentada pelo Conselho Nacional de Arquivos (Conarq) por ser atribuição precípua do referido órgão a definição de políticas de arquivos públicos e privados e orientação normativa que contribuam para a gestão e proteção especial aos documentos de arquivo, seja qual for o suporte”. Neste sentido, destacam-se as ações promovidas pela Câmara Técnica de Documentos Eletrônicos (CTDE) do Conarq, como exemplo, a publicação da Carta para a Preservação do Patrimônio Arquivístico Digital ${ }^{15}$ onde é feito um alerta às organizações públicas e privadas, às instituições de ensino e pesquisa e a todos os setores da sociedade brasileira comprometidos com a inclusão informacional para os seguintes problemas: dependência social da informação digital, rápida obsolescência da tecnologia digital, incapacidade dos atuais sistemas eletrônicos de informação em assegurar a preservação de longo prazo, fragilidade intrínseca do armazenamento digital, complexidade e custos da preservação digital e a multiplicidade de atores envolvidos.

Neste sentido, Innareli ${ }^{16}$ destaca que "as instituições responsáveis pela gestão documental são afetadas diretamente por essa 'inundação' tecnológica, pois como já foi dito anteriormente, conceitos e técnicas de gestão documental foram atropelados em nome da eficiência administrativa e pela falta de visão dos administradores e informáticos sobre o tratamento do documento digital, principalmente documentos digitais permanentes ou de longa guarda". Além disso, com tais avanços das Tecnologias da Informação e Comunicação (TIC) em que as funções administrativas se modernizaram, é possível dizer que "a demanda por documentos digitais tem sido inversamente proporcional aos avanços na pesquisa em preservação digital, de modo que documentos estão sendo produzidos sem garantias de que haverá conhecimentos suficientes e tecnologias capazes de preservá-los”"

Ainda conforme Innarelli1 ${ }^{16}$ "os documentos digitais são gerados e incorporados aos sistemas informatizados tendo como ponto de vista seu uso primário e sua operacionalização, com pouca ou nenhuma preocupação em relação à sua gestão e preservação". Este é um dos principais problemas relacionados à preservação digital, visto que tal incorporação não é acompanhada e definida por arquivistas, o que pode ocasionar problemas relacionados à gestão de documentos. No que diz respeito ao tratamento arquivístico, os documentos arquivísticos digitais apresentam diversas especificidades, visto que "há notáveis mudanças quanto às atividades de criação, aquisição, classificação, avaliação, descrição, conservação e acesso"18.

Vale inicialmente destacar a distinção entre o documento nato digital e o documento digitalizado, visto que os documentos nato digitais são aqueles "produzidos originalmente em formato digital", ao tempo que o documento digitalizado é "o representante digital do processo de digitalização do documento físico e seus metadados" ${ }^{\prime 1}$. Por natureza, o documento arquivístico digital é nato-digital. Desta forma, o documento arquivístico digital é compreendido como "uma unidade indivisível de informação constituída por uma mensagem fixada num suporte (registrada), com uma sintática estável”, "produzido e/ou recebido por uma pessoa física ou jurídica, no decorrer de suas atividades", "codificado em dígitos binários e interpretável por um sistema computacional”, "em suporte magnético, óptico ou outro"13.

Apesar de não haver consenso na área, do ponto de vista diplomático, Rondinelli13 destaca as seguintes características de um documento arquivístico digital: forma fixa, conteúdo estável, relação orgânica, 
contexto identificável, ação e o envolvimento de até cinco pessoas (autor, redator, destinatário, originador e produtor). O Quadro 2 detalha tais características.

\section{Quadro 2 - Elementos característicos de um Documento Arquivistico Digital}

\begin{tabular}{|l|l|}
\hline Características & Descrição \\
\hline $\begin{array}{l}\text { Forma fixa e conteúdo } \\
\text { estável }\end{array}$ & $\begin{array}{l}\text { O documento arquivístico digital deve possuir a mesma apresentação do momento } \\
\text { em que foi criado. Caracteriza-se por ser uma unidade indivisível de informação } \\
\text { fixada em um suporte com uma sintática estável. }\end{array}$ \\
\hline Relação orgânica & $\begin{array}{l}\text { Característica arquivística segundo a qual à medida que os documentos são } \\
\text { criados os registros de tais atividades são armazenados e apresentam uma } \\
\text { vinculação inexorável entre si. }\end{array}$ \\
\hline Ação & $\begin{array}{l}\text { Trata-se de uma hierarquia de estruturas fora do documento arquivístico, tais } \\
\text { como, os contexto: jurídico-administrativo (leis, normas etc.), de proveniência } \\
\text { (organogramas, regimentos e regulamentos), de procedimentos (normas internas } \\
\text { referentes aos documentos da instituição), documental (códigos de classificação, } \\
\text { guias, índices etc.) e tecnológico (hardware, software, metadados e padrões). }\end{array}$ \\
\hline Envolvimento de pessoas & $\begin{array}{l}\text { Refere-se ao fato dos documentos arquivísticos refletirem ações e evidenciarem a } \\
\text { realização das atividades organizacionais. }\end{array}$ \\
\hline $\begin{array}{l}\text { Tal característica, advinda da diplomática, atribui à produção de um documento } \\
\text { arquivístico a participação de até cinco pessoas (ou ao menos três): o autor } \\
\text { (pessoa que possui autoridade para emitir o documento); o redator (pessoa que } \\
\text { possui competência para articular o conteúdo do documento); o destinatário } \\
\text { (pessoa a quem o documento é dirigido); o originador (pessoa designada no } \\
\text { endereço eletrônico no qual o documento foi gerado); e, por fim, o produtor } \\
\text { (pessoa a quem o documento pertence). }\end{array}$ \\
\hline
\end{tabular}

Fonte: Adaptado de Duranti e Preston (2008) ${ }^{20}$ e Rondinelli (2013)

Vale também destacar a diferença entre o documento digital e o eletrônico. Conforme Rondinellii3 , "podese dizer que todo documento digital é eletrônico, mas nem todo documento eletrônico é digital. Um exemplo seria uma fita cassete, cujo som, embora necessite de equipamento eletrônico para ser ouvido, não é codificado em bits”. Desta forma, os documentos arquivísticos digitais são constituídos por determinadas partes, tais como: forma documental, anotações, contexto, suporte, atributos e componentes digitais ${ }^{13}$.

No que diz respeito ao componente digital, característica dos documentos digitais, salienta-se que os componentes digitais destes documentos são codificados "em dígitos binários (O-I) por um software ou sequência de softwares (Word, Ascii, por exemplo); o conjunto desses dígitos forma uma cadeia de bits; essa cadeia é decodificada pelo mesmo software ou sequência de softwares, permitindo que o documento seja apresentado na tela do computador. Daí se deduz que não é possível manter um documento digital exatamente como o vemos, a não ser que o imprimamos - e nesse caso ele deixaria de ser digital. O que se pode manter é a capacidade de reproduzir o documento sempre que necessário"13.

Desta forma, preservar significa "prover intervenções técnicas, científicas e políticas, de tal forma que a informação registrada em qualquer suporte material tenha permanência e durabilidade e possa ser acessada física e logicamente, de forma contínua e pelo maior tempo possível”21. Owens ${ }^{22}$, ao tratar sobre preservação digital, estabelece dezesseis axiomas orientadores, conforme apresentado no Quadro 3. 


\section{Quadro 3 - Axiomas referentes à preservação digital}

\begin{tabular}{|c|c|}
\hline Axiomas & Características \\
\hline Um repositório não é um software. & $\begin{array}{l}\text { Um repositório é um conjunto de recursos financeiros, de hardware, de } \\
\text { tempo, de trabalho em equipe e implementação contínua de políticas e } \\
\text { planejamento. }\end{array}$ \\
\hline As instituições fazem a preservação. & $\begin{array}{l}\text { Sem ações de preservação, os objetos digitais existirão apenas durante o } \\
\text { período relacionado à durabilidade da mídia. }\end{array}$ \\
\hline $\begin{array}{l}\text { As ferramentas podem tanto ajudar } \\
\text { quanto atrapalhar. }\end{array}$ & $\begin{array}{l}\text { Ferramentas e softwares especializados em preservação digital possuem a } \\
\text { mesma possibilidade de atrapalhar ou de ajudar na solução de um problema } \\
\text { de preservação digital. }\end{array}$ \\
\hline $\begin{array}{l}\text { Nada tem sido preservado, são } \\
\text { apenas objetos sendo guardados. }\end{array}$ & $\begin{array}{l}\text { Se deseja avaliar a seriedade com que uma organização trata da } \\
\text { preservação digital, não comece analisando seus códigos, sua arquitetura de } \\
\text { armazenamento ou conversando com seus desenvolvedores. Veja na área } \\
\text { financeira como a preservação digital aparece no orçamento. }\end{array}$ \\
\hline Acumulação não é preservação. & $\begin{array}{l}\text { Para realmente preservar algo, é preciso torná-lo detectável e acessível. Isto } \\
\text { exigirá que os processos associados, como, por exemplo, à descrição e aos } \\
\text { métodos de armazenamento possuam uma abordagem clara e coerente. }\end{array}$ \\
\hline $\begin{array}{l}\text { Fazer backup de dados não é } \\
\text { preservação digital. }\end{array}$ & $\begin{array}{l}\text { Muitos dos aspectos relacionados ao backup de dados são similares ao } \\
\text { trabalho de preservação digital, mas a preocupação para recuperar dados a } \\
\text { curto prazo é diferente das questões referentes a longo prazo relacionadas } \\
\text { à garantia de acesso ao conteúdo no futuro. }\end{array}$ \\
\hline $\begin{array}{l}\text { As fronteiras dos objetos digitais são } \\
\text { confusas. }\end{array}$ & $\begin{array}{l}\text { Objetos digitais fazem referência, incorporam e usam aspectos de outros } \\
\text { objetos digitais como parte de sua função cotidiana. É um desafio articular o } \\
\text { que faz parte do seu objeto e o que é externo a ele. }\end{array}$ \\
\hline $\begin{array}{l}\text { Uma coleção digital de uma pessoa é } \\
\text { diferente de um objeto digital, que é } \\
\text { diferente de um conjunto de dados. }\end{array}$ & $\begin{array}{l}\text { Em alguns casos, o conteúdo de um disco rígido pode ser gerenciado como } \\
\text { um único item e, em outros casos, como um conjunto de itens. }\end{array}$ \\
\hline $\begin{array}{l}\text { Preservação digital é fazer o melhor } \\
\text { uso dos recursos disponíveis } \\
\text { para reduzir as ameaças e riscos } \\
\text { iminentes. }\end{array}$ & $\begin{array}{l}\text { Preservação digital é um processo contínuo de compreensão dos riscos } \\
\text { a serem enfrentados pela perda de um conteúdo ou pela capacidade de } \\
\text { renderizá-lo e interagir com ele. }\end{array}$ \\
\hline $\begin{array}{l}\text { A resposta para quase todas as } \\
\text { questões de preservação digital é: } \\
\text { "isto depende". }\end{array}$ & $\begin{array}{l}\text { Decidir o que é importante sobre um objeto ou um conjunto de objetos } \\
\text { depende em grande parte do que possa ser o seu uso no futuro. }\end{array}$ \\
\hline Já passou da hora de começar a agir. & $\begin{array}{l}\text { Existem processos e atividades práticas que todos podem e devem começar } \\
\text { a fazer para mitigar muito dos riscos iminentes de perda. }\end{array}$ \\
\hline $\begin{array}{l}\text { Técnicas altamente avançadas de } \\
\text { preservação digital podem silenciar o } \\
\text { passado. }\end{array}$ & $\begin{array}{l}\text { Um quadro altamente técnico de preservação digital resulta em que muitas } \\
\text { instituições menores e com menos recursos sentem que simplesmente não } \\
\text { podem fazer a preservação digital ou que precisam contratar consultores } \\
\text { para informá-los sobre padrões complexos de metadados, sendo que, o que } \\
\text { precisam fazer primeiro, é uma cópia de seus arquivos. }\end{array}$ \\
\hline $\begin{array}{l}\text { Os recursos relacionados à mídia } \\
\text { digital levam ao desenvolvimento de } \\
\text { recursos associados à preservação } \\
\text { digital. }\end{array}$ & $\begin{array}{l}\text { As mídias digitais oferecem novas e significativas oportunidades para } \\
\text { o envolvimento com comunidades voltadas para o desenvolvimento de } \\
\text { soluções digitais para preservação. }\end{array}$ \\
\hline Aceite e abrace uma parte do arquivo. & $\begin{array}{l}\text { Não termos condições de salvar por um longo prazo a maioria dos objetos } \\
\text { digitais. Quando se começa a entender isto, o foco e a energia passam a ser } \\
\text { direcionados para os objetos mais importantes. }\end{array}$ \\
\hline $\begin{array}{l}\text { A escala e as estruturas inerentes à } \\
\text { informação digital sugerem trabalhar } \\
\text { com uma "pá" e não com uma } \\
\text { "pinça". }\end{array}$ & $\begin{array}{l}\text { As decisões relacionadas à preservação digital devem ser tomadas, em } \\
\text { vez de individualmente, em escala. Os requisitos computacionais das } \\
\text { informações digitais e os arquivos digitais com quantidades significativas de } \\
\text { metadados possibilitam as ações em lote. }\end{array}$ \\
\hline $\begin{array}{l}\text { Estabeleça exigências de preservação } \\
\text { digital pensando como um futurista. }\end{array}$ & $\begin{array}{l}\text { Não se sabe as ferramentas que as pessoas utilizarão no futuro. Entretanto, } \\
\text { precisa-se estar atento às tendências no desenvolvimento das tecnologias } \\
\text { digitais. }\end{array}$ \\
\hline
\end{tabular}

Fonte: Adaptado de Owens (2018) ${ }^{22}$. 
A preservação digital garantirá o acesso às informações para as gerações futuras na área da saúde, principalmente por meio dos Sistemas de Informação em Saúde e dos Repositórios Arquivísticos do SUS. Os axiomas referentes à preservação digital devem ser utilizados como agentes norteadores para a organização, tratamento e armazenamento dos documentos arquivísticos digitais em qualquer organização. Vale destacar que fazer preservação digital envolve a realização de investimentos, dessa forma, é possível afirmar que não existe preservação digital sem alocação de recursos, sejam eles humanos, equipamentos, imóveis etc.

\section{METODOLOGIA}

Esta pesquisa, quanto à sua finalidade, caracteriza-se como aplicada por buscar adquirir conhecimentos para a solução de um determinado problema. Quanto aos seus objetivos, trata-se de uma pesquisa exploratória e, em relação aos métodos empregados, utilizam-se as abordagens quantitativa e qualitativa. Ela possui como universo de pesquisa a legislação em saúde vigente no Estado brasileiro e utiliza como amostra os textos completos da Consolidação das Normas Infralegais do SUS ${ }^{23,24}$.

Com base no que foi exposto até então, este trabalho adota como ponto de partida o seguinte problema de pesquisa: a necessidade da adoção de políticas governamentais relacionadas à preservação digital no âmbito dos sistemas e serviços de saúde. Para isto, esta pesquisa possui o objetivo de identificar ações governamentais no âmbito dos sistemas e serviços de saúde que visam à adoção de políticas públicas relacionadas à preservação digital em saúde.

Em atenção à Lei Complementar n. ${ }^{0}$ 95²5, de 26 de fevereiro de 1998, o Ministério da Saúde publicou, em 3 de outubro de 2017, seis Portarias de Consolidação (PRC) referentes à consolidação das normas do Gabinete do Ministro publicadas desde 1990 até 28 de setembro de 2017. Salienta-se que, mesmo com a publicação das PRC em 2017, estas normas continuam sendo modificadas/atualizadas por meio dos dispositivos legais vigentes.

Conforme informação existente no sítio do Ministério da Saúde, a consolidação das portarias "foi executada, por intermédio de um Termo de Execução Descentralizada (projeto de pesquisa), pelo Programa de Direito Sanitário da Fiocruz, com a participação de pesquisadores da Faculdade de Direito da Universidade de Brasília - UnB e envolvimento de todas as secretarias do Ministério da Saúde, em articulação direta com a equipe do projeto. O projeto de pesquisa, apoiado pelo Ministério da Saúde e pactuado previamente com Conass e Conasems, foi implementado sob a coordenação do Prodisa/Fiocruz e reuniu especialistas de diversas áreas do saber, tais como medicina, saúde pública, direito sanitário, direito regulatório, ciência da informação, biblioteconomia e ciência da computação”26.

As portarias de Consolidação estão disponíveis no portal do Ministério da Saúde por meio do Saúde Legis $^{27}$, um sistema de consulta da legislação do SUS. Existe um total de seis Portarias de Consolidação vigentes e que tratam respectivamente dos seguintes assuntos: 1) Direitos e deveres dos usuários de saúde, a organização e o funcionamento do $\operatorname{SUS}^{28}$ 2) Políticas nacionais de saúde do SUS ${ }^{29}$ 3) Redes de Atenção do SUS $^{30} 4$ ) Sistemas e subsistemas do SUS ${ }^{31}$ 5) As ações e os serviços de saúde do SUS $^{32}$ e 6) Financiamento e a transferência dos recursos federais para as ações e os serviços de saúde do SUS ${ }^{33}$.

Este trabalho adotou como procedimento a pesquisa documental e como técnica de coleta e análise dos dados a análise de conteúdo. Bardin ${ }^{34}$ evidencia que o objetivo da análise de conteúdo, ao especificar as diferenças essenciais entre análise documental e análise conteúdo, é “a manipulação de mensagens (conteúdo e expressão desse conteúdo) para evidenciar os indicadores que permitam inferir sobre uma outra realidade que não a da mensagem". A análise das Portarias de Consolidação foi realizada de acordo com as seguintes fases (Quadro 4). 


\section{Quadro 4-Fases da análise de conteúdo}

\begin{tabular}{|l|l|}
\hline Fase & Descrição \\
\hline Pré-análise & $\begin{array}{l}\text { Fase que possui por objetivo operacionalizar o desenvolvimento do trabalho e } \\
\text { sistematizar as ações a serem realizadas. Nesta fase, foi realizada a leitura flutuante; } \\
\text { a escolha dos textos a serem analisados; a formulação de possíveis hipóteses e } \\
\text { objetivos; a referenciação de índices e a elaboração de indicadores; e a preparação } \\
\text { do material. }\end{array}$ \\
\hline Exploração do material & $\begin{array}{l}\text { Trata-se da aplicação das decisões tomadas na fase de pré-análise. Nesta fase, foram } \\
\text { realizadas operações de codificação, decomposição ou enumeração, conforme as } \\
\text { regras previamente estabelecidas. }\end{array}$ \\
\hline $\begin{array}{l}\text { Tratamento dos resultados } \\
\text { obtidos e interpretação }\end{array}$ & $\begin{array}{l}\text { Esta fase compreendeu o tratamento dos dados brutos de forma que passassem } \\
\text { a ser significativos. Estes resultados possibilitaram a realização de inferências e } \\
\text { proposições relacionadas aos objetivos previstos. }\end{array}$ \\
\hline
\end{tabular}

Fonte: Adaptado de Bardin (2011) ${ }^{34}$.

Com base no objetivo proposto neste artigo, definiu-se na fase de pré-análise que seriam utilizados como expressões de busca nas PRC os termos: 'informação' (e variações da palavra, a exemplo: ‘informações'), ‘documento’ e 'arquivo'. A predefinição destas categorias de análise se deu pelo motivo destes termos estarem intrinsecamente associados à teoria, aos procedimentos e às técnicas arquivísticas.

A coleta de dados foi realizada em 1 de maio de 2020, e os documentos obtidos foram agrupados em um único arquivo para facilitar a normalização dos registros, a análise e a interpretação dos resultados. A estatística descritiva foi utilizada como técnica de análise e interpretação das informações levantadas. Na seção a seguir, são apresentados os resultados encontrados.

\section{ANÁLISE DOS RESULTADOS}

Incialmente foi verificada, conforme estabelecido na fase de pré-análise, a frequência dos termos ‘informação' (considerados os termos ‘informação’ e ‘informações'), ‘documento’ e ‘arquivo’ (Tabela o1). O termo 'informação', quando totalizado o somatório de todas as portarias consolidadas, é o que possui a maior frequência com 2.745 ocorrências. Em seguida, o termo 'documento', com 640 ocorrências e, por último, o termo 'arquivo', com 110 ocorrências. Nesta etapa, para fins de quantificação, foram consideradas todas as ocorrências dos termos predefinidos. Na pré-análise, a menor ocorrência dos termos 'documento' e 'arquivos', respectivamente, pode ser um indício da falta de critérios relacionados ao tratamento e organização dos documentos arquivísticos. A ocorrência do termo "documento", assim como do termo 'arquivo', está, em muitos dos casos, associada à utilização destes enquanto objetos para registros de atividades administrativas no âmbito das ações do Ministério da Saúde. Além disto, constata-se ainda que tais termos, 'documento' e 'arquivo', são tratados como sinônimos em determinados momentos. 
Tabela 01 - Frequência de palavras referentes aos termos de busca utilizados

\begin{tabular}{|l|c|c|c|}
\multicolumn{1}{|c|}{ Portaria Consolidada } & \multicolumn{2}{c|}{ Termos de busca } \\
\cline { 2 - 4 } & Informação & Documento & Arquivo \\
\hline $\begin{array}{l}\text { 1) Direitos e deveres dos usuários de saúde, a organização e o } \\
\text { funcionamento do SUS }\end{array}$ & 513 & 108 & 38 \\
\hline 2) Políticas nacionais de saúde do SUS & 626 & 111 & 8 \\
\hline 3) Redes de Atenção do SUS & 281 & 67 & 10 \\
\hline 4) Sistemas e subsistemas do SUS & 218 & 47 & 21 \\
\hline 5) Ações e os serviços de saúde do SUS & 810 & 191 & 27 \\
\hline $\begin{array}{l}\text { 6) Financiamento e a transferência dos recursos federais para as } \\
\text { ações e os serviços de saúde do SUS }\end{array}$ & 297 & 116 & 6 \\
\hline Total & $\mathbf{2 . 7 4 5}$ & $\mathbf{6 4 0}$ & $\mathbf{1 1 0}$ \\
\hline
\end{tabular}

Fonte: $\mathrm{O}$ autor (2020).

Com base no que foi apresentado na Tabela 01, e buscando verticalizar a análise de conteúdo com foco na preservação digital, buscou-se pelos termos 'digital' e 'eletrônico' nas portarias de consolidação. Vale lembrar que todo documento digital é eletrônico, entretanto nem todo documento eletrônico é digital, visto que o que distingue o documento digital é a forma de registro da informação, neste caso, em dígitos binários $^{13}$. A estratégia de escolha destes termos se deu com o intuito de localizar elementos relacionados à preservação digital. A Tabela 02 apresenta a frequência de ocorrência dos termos escolhidos estratificados por cada uma das portarias consolidadas.

Tabela 02 - Frequência dos termos digital e eletrônico

\begin{tabular}{|l|c|c|}
\multicolumn{1}{|c|}{ Portaria Consolidada } & \multicolumn{2}{c|}{ Termos de busca } \\
\cline { 2 - 3 } & digital & eletrônico \\
\hline $\begin{array}{l}\text { 1) Direitos e deveres dos usuários de saúde, a organização e o } \\
\text { funcionamento do SUS }\end{array}$ & 23 & 112 \\
\hline 2) Políticas nacionais de saúde do SUS & 5 & 39 \\
\hline 3) Redes de Atenção do SUS & 1 & 43 \\
\hline 4) Sistemas e subsistemas do SUS & 1 & 19 \\
\hline 5) Ações e os serviços de saúde do SUS & 9 & 135 \\
\hline $\begin{array}{l}\text { 6) Financiamento e a transferência dos recursos federais para as ações e } \\
\text { os serviços de saúde do SUS }\end{array}$ & 0 & 113 \\
\hline Total & 39 & $\mathbf{4 6 1}$ \\
\hline
\end{tabular}

Fonte: O autor (2020).

Na Tabela 2 constata-se uma ocorrência muito maior do termo 'eletrônico' (461 resultados) em relação ao termo 'digital' (39 ocorrências). Os termos que se referiam a outras temáticas, tais como: termômetro digital, punção digital, impressão digital, entre outros, foram retirados da amostra. No sentido de conhecer as circunstâncias da utilização do termo 'digital', foi elaborado o Gráfico 01 com a frequência de assuntos relacionados. 


\section{Gráfico 01 - Frequência de assuntos relacionados à ocorrência do termo digital}

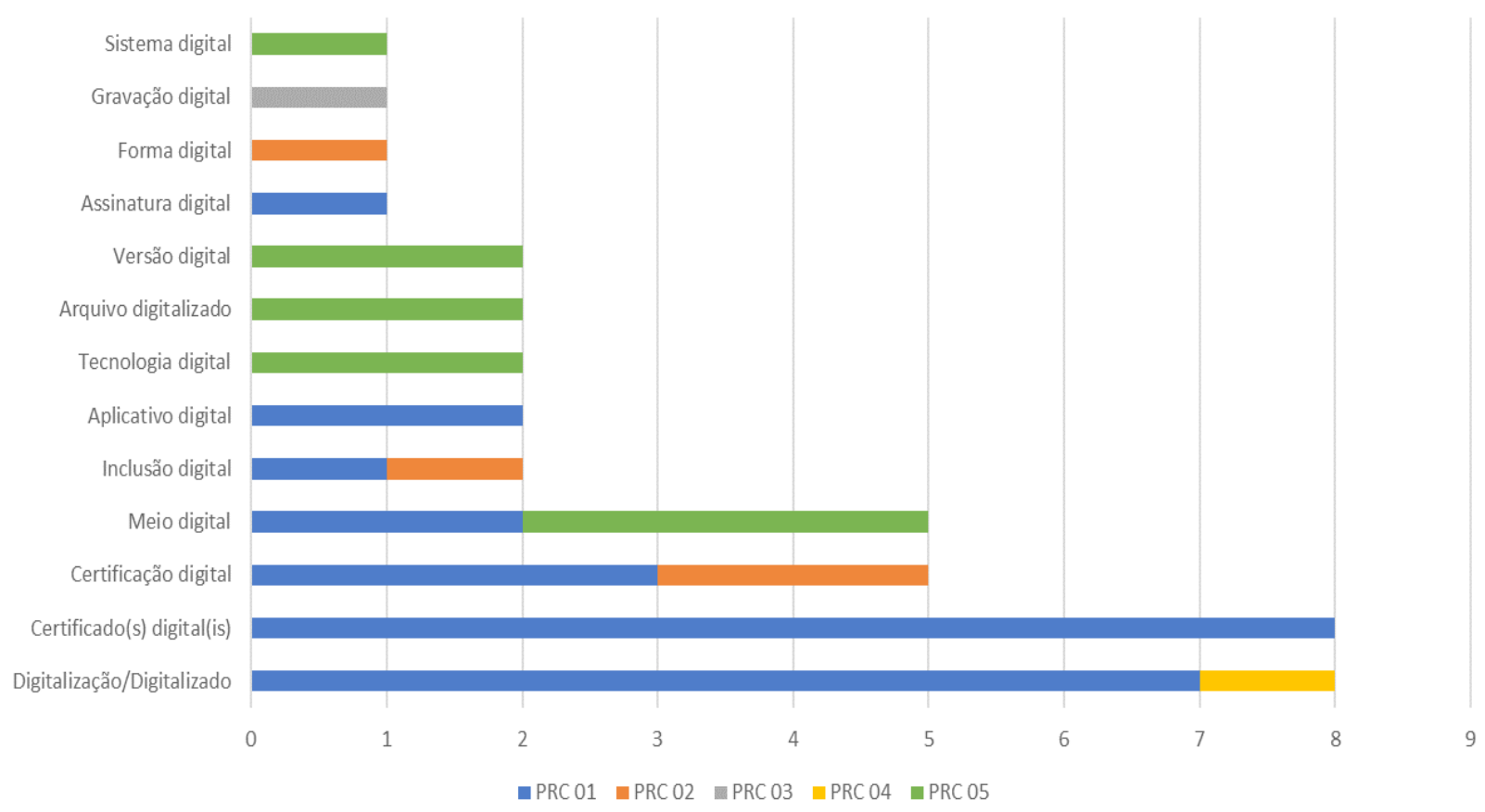

Fonte: O autor (2020).

A amostra totalizou 40 resultados e evidencia que a maior ocorrência dos assuntos associados ao termo 'digital' (Gráfico 01) está nas Portarias Consolidadas 01 (Direitos e deveres dos usuários de saúde, a organização e o funcionamento do SUS) e 05 (Ações e os serviços de saúde do SUS), respectivamente com 60\% (24 ocorrências) e 25\% (dez ocorrências). Chama atenção o fato da PRC o6 (Financiamento e a transferência dos recursos federais para as ações e os serviços de saúde do SUS) não ter apresentado ocorrências de assuntos associados ao termo 'digital'.

Os assuntos de maior ocorrência (Gráfico o1) foram os associados à 'digitalização' e a 'certificado(s) digital(is)' (oito ocorrências cada). Pode-se inferir, com base em tais resultados, que tanto a digitalização de documentos como a utilização da assinatura digital possivelmente são práticas adotadas no âmbito do Ministério da Saúde. Entretanto, vale salientar que, para fins de preservação digital, devem ser adotados, tanto para os documentos digitalizados quanto para os documentos nato digitais, os critérios arquivísticos de preservação digital.

Em relação ao uso do termo 'eletrônico', o assunto de maior ocorrência nos resultados é 'endereço eletrônico' (236 resultados). Entretanto, para obter uma melhor visualização, por ele sempre fazer referência ao acesso a endereços eletrônicos disponibilizados no âmbito do Ministério da Saúde, este termo foi retirado da amostra. Também foram retirados termos como 'sítio eletrônico' (17 resultados), 'página eletrônica' (nove resultados), 'portal eletrônico' (dois resultados), 'espaço eletrônico' (um resultado) e 'canal eletrônico' (um resultado). Com base em tais resultados, é possível constatar que não existe uma padronização nos termos associados ao direcionamento a endereços eletrônicos por parte do Ministério da Saúde. A Tabela 02 apresenta os assuntos associados ao termo 'eletrônico' e presentes nas portarias de consolidação. 


\section{Gráfico 02 - Frequência de assuntos relacionados à ocorrência do termo eletrônico}

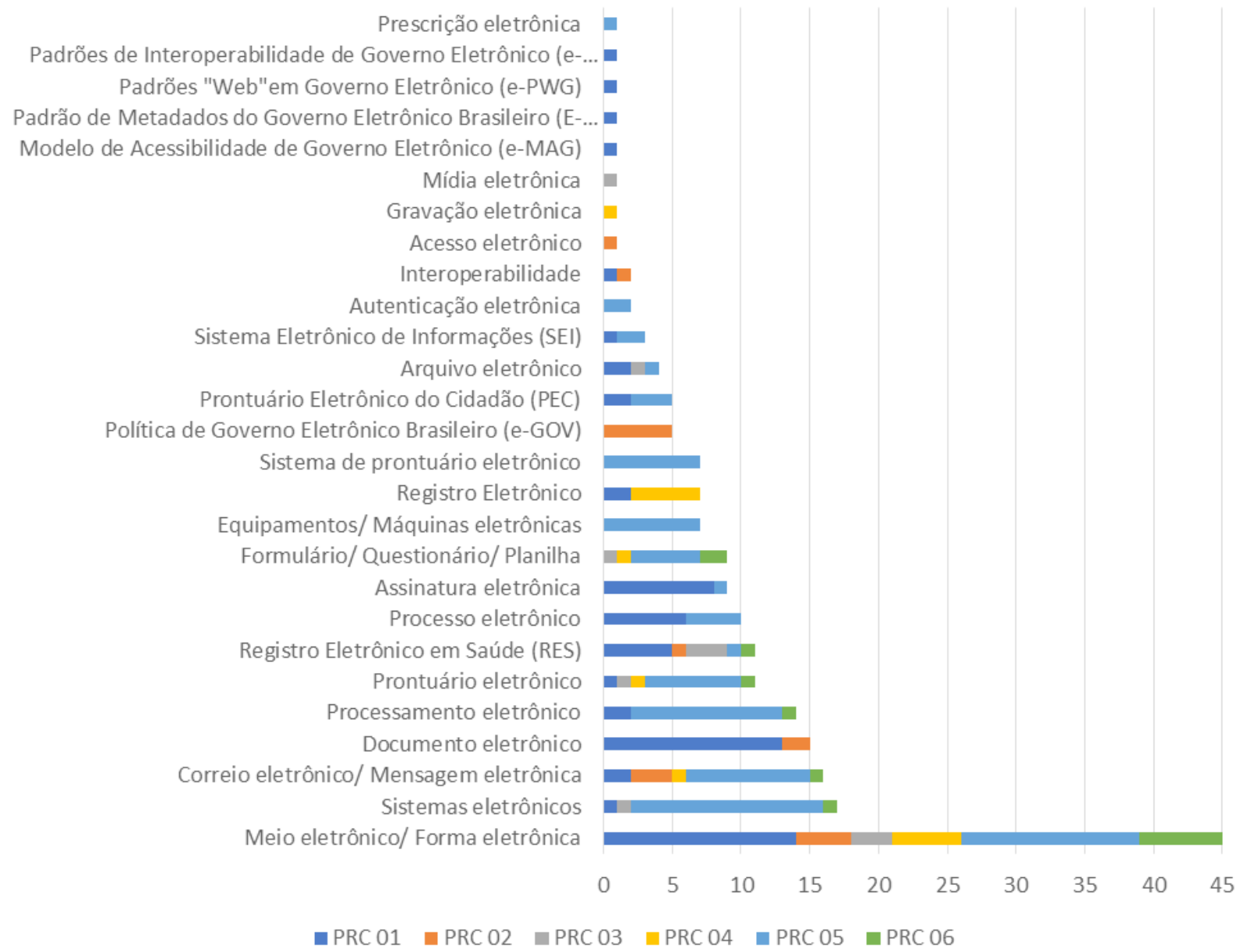

Fonte: O autor (2020).

O assunto de maior ocorrência do Gráfico 02 se refere à forma ou ao meio de transmissão das informações, no caso 'meio eletrônico/forma eletrônica' com 23,6\% da amostra (45 resultados). Em seguida, aparecem os assuntos relacionados a 'sistemas eletrônicos' com 8,9\% (17 resultados), 'correio eletrônico/mensagem eletrônica' com 8,4\% (16 resultados) e 'documento eletrônico' com 7,9\% (15 resultados). Chama atenção na amostra também os 'Registros Eletrônicos em Saúde (RES)' com 5,8\% (11 resultados) e a 'assinatura eletrônica' com 4,7\% (9 resultados). Verifica-se nos resultados a presença tanto do termo 'assinatura digital' quanto 'assinatura eletrônica'.

A Política de Governo Eletrônico Brasileiro (e-GOV) apresentou um percentual de 2,6\% da amostra (o governo adota atualmente a nomenclatura 'Governo Digital'). Apesar de não apresentarem um percentual significativo, com 0,5\% (uma ocorrência), vale ressaltar a importância dos seguintes documentos presentes nos resultados, são eles: Modelo de Acessibilidade de Governo Eletrônico (e-MAG) ${ }^{35}$, Padrão de Metadados do Governo Eletrônico Brasileiro (E-PMG) ${ }^{36}$, Padrões 'Web' em Governo Eletrônico (e-PWG) ${ }^{37}$ e Padrões de Interoperabilidade de Governo Eletrônico (e-PING) ${ }^{38}$. Pode-se inferir que as políticas públicas de governo relacionadas aos ambientes digitais, apesar de serem conhecidas no âmbito do Ministério da Saúde, seus objetivos e características não estão devidamente explicitadas nas normas vigentes. O Quadro 03 apresenta os objetivos de tais documentos. 


\section{Quadro 03 - Políticas Públicas de Governo Eletrônico}

\begin{tabular}{|l|l|}
\hline Documento & Objetivo \\
\hline $\begin{array}{l}\text { Modelo de Acessibilidade de Governo } \\
\text { Eletrônico (e-MAG) }\end{array}$ & $\begin{array}{l}\text { Documento com recomendações para que o processo de } \\
\text { acessibilidade dos sítios e portais do governo brasileiro seja } \\
\text { conduzido de forma padronizada e de fácil implementação. }\end{array}$ \\
\hline $\begin{array}{l}\text { Padrões de Interoperabilidade de Governo } \\
\text { Eletrônico (e-PING) }\end{array}$ & $\begin{array}{l}\text { Define um conjunto mínimo de premissas, políticas e especificações } \\
\text { técnicas que regulamentam a utilização da Tecnologia de } \\
\text { Informação e Comunicação no Governo Federal, estabelecendo } \\
\text { as condições de interação com os demais Poderes e esferas de } \\
\text { governo e com a sociedade em geral. }\end{array}$ \\
\hline $\begin{array}{l}\text { Padrão de Metadados do Governo Eletrônico } \\
\text { Brasileiro (E-PMG) }\end{array}$ & $\begin{array}{l}\text { O documento estabelece um conjunto mínimo de elementos que } \\
\text { contém dados necessários para a recuperação e gerenciamento de } \\
\text { informações. }\end{array}$ \\
\hline $\begin{array}{l}\text { Padrões ‘Web’ em Governo Eletrônico } \\
\text { (e-PWG) }\end{array}$ & $\begin{array}{l}\text { O documento fornece recomendações de boas práticas na área } \\
\text { digital, com o objetivo de aprimorar a comunicação, o fornecimento } \\
\text { de informações e serviços prestados por meios eletrônicos pelos } \\
\text { órgãos do Governo Federal. }\end{array}$ \\
\hline
\end{tabular}

Fonte: O autor (2020).

Destaca-se, também, na análise dos resultados, o termo 'interoperabilidade', com 48 ocorrências ao todo. Ao realizar a busca pelo termo 'preservação', associado à questão documental nas seis portarias consolidadas, foram localizados apenas quatro resultados (Quadro 04). Destaque para referência à Política Nacional de Informação e Informática em Saúde (PNIIS) ${ }^{39}$ na PRC 02.

\section{Quadro 04 - Assuntos relacionados ao termo preservação}

\begin{tabular}{|c|c|c|}
\hline $\begin{array}{l}\text { Portaria } \\
\text { Consolidada }\end{array}$ & Capítulo & Resultado da busca \\
\hline \multirow{3}{*}{ PRC 01} & \multirow[t]{2}{*}{$\begin{array}{l}\text { Dos sistemas de } \\
\text { informação da } \\
\text { Atenção à saúde }\end{array}$} & $\begin{array}{l}\text { Art. 281. O Ministério da Saúde será o responsável pela gestão do Portal de } \\
\text { Saúde do Cidadão e executará: (Origem: PRT MS/GM 940/2011, Art. 28) } \\
\text { II - preservação da estabilidade, segurança e funcionalidade da rede, por meio } \\
\text { de medidas técnicas compatíveis com os padrões internacionais e do estímulo } \\
\text { ao uso de boas práticas; (Origem: PRT MS/GM 940/2011, Art. 28, II) }\end{array}$ \\
\hline & & $\begin{array}{l}\text { Art. 330. É de responsabilidade do DATASUS manter atualizado o banco } \\
\text { de dados de produção nos aplicativos TABWIN e TABNET, inclusive com a } \\
\text { preservação da série histórica. (Origem: PRT MS/GM 321/2007, Art. 11) }\end{array}$ \\
\hline & $\begin{array}{l}\text { Do SIN- } \\
\text { PROCESSO }\end{array}$ & $\begin{array}{l}\text { Art. 500. O tratamento arquivístico, inclusive a eliminação de documentos } \\
\text { e processos eletrônicos, observará os procedimentos de gestão documental } \\
\text { adotados no âmbito do Ministério da Saúde. (Origem: PRT MS/GM } \\
2758 / 2013 \text {, Art. } 16 \text { ) } \\
\S 2^{\circ} \text { Ato específico definirá plano de preservação de documentos } \\
\text { eletrônicos. (Origem: PRT MS/GM } 2758 / 2013 \text {, Art. } 16, \S 2^{\circ} \text { ) }\end{array}$ \\
\hline PRC 02 & $\begin{array}{l}\text { Dos Princípios } \\
\text { Gerais da PNIIS }\end{array}$ & $\begin{array}{l}\text { Art. } 4^{0} \text { Constituem princípios gerais da PNIIS: (Origem: PRT MS/GM } \\
\text { 589/2015, Art. } 4^{\circ} \text { ) } \\
\text { VIII - preservação da autenticidade e da integridade da informação em } \\
\text { saúde; e (Origem: PRT MS/GM 589/2015, Art. 40, VIII) }\end{array}$ \\
\hline
\end{tabular}

Fonte: O autor (2020). 
Desta forma, é possível afirmar que as políticas públicas de informação relacionadas à preservação digital em saúde, e aquelas associadas ao governo digital, não estão explicitadas nos dispositivos vigentes no âmbito do Ministério da Saúde. Esses atos normativos fazem referência a documentos que tratam de temas relacionados aos ambientes digitais, entretanto, não explicitam como estas ações devem ocorrer por meio de seus dispositivos normativos. Ressalta-se ainda que, por entender que não diz respeito apenas a softwares e hardwares, as ações voltadas para a preservação digital em saúde precisam ser aperfeiçoadas de modo a alcançar a todos os profissionais e pessoas envolvidas na área da saúde, além de ser recomendável que estas sejam devidamente explicitadas.

\section{CONSIDERAÇÕES FINAIS}

O objetivo deste artigo foi identificar ações governamentais no âmbito dos sistemas e serviços de saúde que visam à adoção de políticas públicas relacionadas à preservação digital em saúde. Desta forma, é possível inferir que, no âmbito do Ministério da Saúde, as ações explicitadas por meio de normas no que diz respeito à preservação digital são incipientes. Existe uma clara necessidade de aperfeiçoamento destes dispositivos para potencializar as ações voltadas para a preservação digital na área da saúde.

No que diz respeito aos dados analisados, é possível inferir que o uso de determinados termos, a exemplo, 'assinatura digital' e 'assinatura eletrônica', precisam ser padronizados. A padronização é essencial para o possível diálogo entre as áreas do conhecimento. É importante também ressaltar que o termo 'arquivo' não seja tratado como sinônimo de 'documento' e destacar que, apesar desta pesquisa ser um recorte de publicações normativas na área de saúde, mesmo assim, se evidencia que as políticas públicas de informação em saúde ainda são incipientes nos dispositivos normativos.

Por fim, destaca-se a importância e a necessidade da capacitação dos profissionais que atuam na área da saúde em relação à organização, tratamento e armazenamento dos documentos; que os gestores e formuladores de políticas incorporem na fase de formulação das políticas públicas de informação em saúde as teorias, procedimentos e técnicas da Arquivologia; e que temáticas como exemplo a preservação digital, os documentos arquivísticos digitais, os sistemas informatizados de gestão arquivística de documentos, os repositórios arquivísticos digitais confiáveis, entre outros, estejam presentes no cotidiano dos responsáveis pelos serviços e sistemas de informação em saúde. Ressalta-se ainda que a participação popular é essencial para o desenvolvimento destas políticas públicas de informação em saúde e para garantir a transparência das ações governamentais.

\section{REFERÊNCIAS}

1. $\quad$ Muller P, Surel Y. A análise das políticas públicas. Pelotas: Educat; 2004.

2. $\quad$ Franzesse C. Administração pública no contexto de mudanças: desafios para o gestor de políticas públicas. In: Ibañez N, Elias PEM, Seixas PHD, organizadores. Política e gestão pública em saúde. São Paulo: Hucitec; 2011. p. 19-53.

3. Silva SCA. A preservação da informação arquivística governamental nas políticas públicas do Brasil. Rio de Janeiro: AAB/FAPERJ, 2008.

4. Souza C. Políticas públicas: uma revisão de literatura. Sociologias. 2006;8(16):431-42.

5. Jardim JM, Políticas públicas de informação: a (não) construção da política nacional de arquivos públicos e privados (1994-2006). In: Anais do $9^{\circ}$ Encontro Nacional de Pesquisa em Ciência da Informação; 2008 set.-out. 28-01; São Paulo, Brasil. São Paulo: Associação Nacional de Pesquisa em Ciência da Informação; 2008. p. 1-17.

6. Sousa RTB. 0 arquivista e as políticas públicas de arquivo. In: Anais do $2^{\circ}$ Congresso Nacional de Arquivologia; 2006 jul. 23-27; Porto Alegre, Brasil. Porto Alegre: ABARQ/UnB; 2006. p. 1-15.

7. Paim JS. O que é o SUS. Rio de Janeiro: Editora Fiocruz; 2009. 
8. Lei no 8080 (BR), de 19 de setembro de 1990. Dispõe sobre as condições para a promoção, proteção e recuperação da saúde, a organização e o funcionamento dos serviços correspondentes e dá outras providências. DOU 1990 set. 20.

9. Constituição 1988 (BR). Constituição da República Federativa do Brasil. Brasília, DF: Centro Gráfico; 1988.

10. Lei no 12.527(BR), de 18 de novembro de 2011. Regula o acesso a informações previsto no inciso XXXIII do art. 50, no inciso II do § $3^{\circ}$ do art. 37 e no $\S 2^{\circ}$ do art. 216 da Constituição Federal; altera a Lei n. ${ }^{8} .112$, de 11 de dezembro de 1990; revoga a Lei n. ${ }^{\circ} 11.111$, de 5 de maio de 2005, e dispositivos da Lei n. 8.159, de 8 de janeiro de 1991; e dá outras providências. DOU 2011 nov. 18.

11. Jardim JM. Políticas públicas arquivísticas: princípios, atores e processos. Arq Adm. 2006;5(2):5-16

12. Schimidt CMS. Arquivologia e a construção do seu objeto científico: concepções, trajetórias, contextualizações [tese]. São Paulo: Escola de Comunicações e Artes da USP; 2012.

13. Rondinelli RC. O documento arquivístico ante a realidade digital: uma revisão necessária. Rio de Janeiro: Editora FGV; 2013.

14. Silva W, Flores D. Política arquivística de preservação digital: um estudo sobre sua aplicabilidade em instituições públicas federais. Perspect Ciênc Inf [Internet]. 2018 [citado em 2020 jun 20];23(3):144-66. Disponível em: https://www.scielo.br/scielo.php?script=sci arttext\&pid=S1413-99362018000300144.

15. Conselho Nacional de Arquivos (BR); Organização das Nações Unidas para a Educação, a Ciência e a Cultura. Câmara Técnica de Documentos Eletrônicos. Carta para preservação do patrimônio arquivístico digital [Internet]. Rio de Janeiro: O Conselho. 2005 [citado em 20 jul. 2020]. Disponível em: http:// conarq.gov.br/images/publicacoes textos/Carta_preservacao.pdf.

16. Innarelli HC. Preservação digital: a influência da gestão dos documentos digitais na preservação da informação e da cultura. Rev Digit Bibliotecon Ciênc Inf [Internet]. 2011 fev. [citado em 2020 jul. 24];9(1):72-7. Disponível em: https://periodicos.sbu.unicamp.br/ojs/index.php/rdbci/article/view/1934.

17. Santos $\mathrm{H}$, Flores $\mathrm{D}$. Preservação do patrimônio documental arquivístico em ambiente digital. Palabra Clave [Internet]. 2017 out. [citado em 2020 jul 20];7(1):e029. Disponível em: https://www. palabraclave.fahce.unlp.edu.ar/article/view/PCe029.

18. Santos HM, Flores D. O documento arquivístico digital enquanto fonte de pesquisa. Perspect Ciênc Inf [Internet]. 2016 [citado em 2020 jul 20];21(4):121-37. Disponível em: http://portaldeperiodicos.eci. ufmg.br/index.php/pci/article/view/2688.

19. Decreto n. ${ }^{\circ} 10.278$ (BR), de 18 de março de 2020. Regulamenta o disposto no inciso $X$ do caput do art. $3^{\circ}$ da Lei n. ${ }^{\circ} 13.874$, de 20 de setembro de 2019, e no art. $2^{\circ}$-A da Lei n. ${ }^{\circ} 12.682$, de 9 de julho de 2012, para estabelecer a técnica e os requisitos para a digitalização de documentos públicos ou privados, a fim de que os documentos digitalizados produzam os mesmos efeitos legais dos documentos originais. DOU [Internet] 2020 mar. 18 [citado em 2020 jul 20]. Disponível em: https://www.in.gov.br/ en/web/dou/-/decreto-n-10.278-de-18-de-marco-de-2020-248810105.

20. Duranti $L$, Preston $R$, editors. International research on permanent authentic records in electronic systems (InterPARES 2): experiential, interactive and dynamic records. Roma: Associazione Nazionale Archivistica Italiana; 2008.

21. Silva SCA. A preservação da informação arquivística governamental nas políticas públicas do Brasil. In: Anais do $9^{\circ}$ Encontro Nacional de Pesquisa em Ciência da Informação; 2008 set.-out. 28-01; São Paulo, Brasil. São Paulo: Associação Nacional de Pesquisa em Ciência da Informação; 2008. p. 1-16.

22. Owens T. The theory and craft of digital preservation. Baltimore: Jhon Hopkins University Press; 2018.

23. Marconi MA, Lakatos EM. Técnicas de pesquisa. 8. Ed. São Paulo: Atlas; 2018.

24. Marconi MA, Lakatos EM. Metodologia científica. 7. Ed. São Paulo: Atlas; 2019.

25. Lei Complementar n. 095 (BR), de 26 de fevereiro de 1998. Dispõe sobre a elaboração, a redação, a alteração e a consolidação das leis, conforme determina o parágrafo único do art. 59 da Constituição Federal, e estabelece normas para a consolidação dos atos normativos que menciona. DOU 1988 fev. 27.

26. Ministério da Saúde (BR). Legislação da saúde: Consolidação das Normas Infralegais do SUS [Internet]. Brasília, DF: O Ministério; 2017 [acesso em 2020 abr. 29]. Disponível em: https://www.saude.gov.br/ legislacao-da-saude. 
27. Sistema de Legislação da Saúde [Internet]. Brasília, DF: Ministério da Saúde; 2017 [versão 2.3.1; acesso em 2020 abr. 29]. Disponível em: https://saudelegis.saude.gov.br/saudelegis/secure/norma/listPublic. xhtml.

28. Portaria de Consolidação nº 01 (BR), de 28 de setembro de 2017. Consolidação das normas sobre os direitos e deveres dos usuários da saúde, a organização e o funcionamento do Sistema Único de Saúde. DOU 2017 set. 28.

29. Portaria de Consolidação no 02 (BR), de 28 de setembro de 2017. Consolidação das normas sobre as políticas nacionais de saúde do Sistema Único de Saúde. DOU 2017 set. 28.

30. Portaria de Consolidação n 03, de 28 de setembro 2017. Consolidação das normas sobre as redes do Sistema Único de Saúde. DOU 2017 set. 28.

31. Portaria de Consolidação no 04 , de 28 de setembro 2017. Consolidação das normas sobre os sistemas e os subsistemas do Sistema Único de Saúde. DOU 2017 set. 28.

32. Portaria de Consolidação $n^{0}$ 05, de 28 de setembro 2017. Consolidação das normas sobre as ações e os serviços de saúde do Sistema Único de Saúde. DOU 2017 set. 28.

33. Portaria de Consolidação nº 06, de 28 de setembro 2017. Consolidação das normas sobre 0 financiamento e a transferência dos recursos federais para as ações e os serviços de saúde do Sistema Único de Saúde. DOU 2017 set. 28.

34. Bardin L. Análise de conteúdo. Reto LA, Pinheiro A, tradutores. São Paulo: Edições 70; 2011.

35. eMAG: Modelo de Acessibilidade em Governo Eletrônico [Internet]. Brasília, DF: Departamento do Governo Eletrônico [versão 3.1; acesso em 2020 abr. 29]; 2014 abr. Disponível em: http://emag. governoeletronico.gov.br/.

36. Governo Brasileiro; Comitê Executivo de Governo Eletrônico. Padrão de Metadados do Governo Eletrônico: e-PMG [Internet]. Brasília, DF: O Comitê; 2014 [versão 1.1; acesso em 2020 jul. 20]. Disponível em: https://www.gov.br/governodigital/pt-br/governanca-de-dados/PMGVersao1_1.pdf/@@ download/file/PMGVersao1 1.pdf.

37. Padrões Web em Governo Eletrônico e-PWG: guia de administração de sítios [Internet]. Brasília, DF: Departamento do Governo Eletrônico; 2011 jan. [versão 1.3; acesso em 2020 jul 20]. Disponível em: http://epwg.governoeletronico.gov.br/guia-administracao.

38. Padrões de Interoperabilidade de Governo eletrônico: e-PING [Internet]. Brasília, DF: Departamento do Governo Eletrônico; 2018 [versão 2018; acesso em 2020 jul. 20]. Disponível em: http://eping. governoeletronico.gov.br/.

39. Ministério da Saúde (BR). Política Nacional de Informação e Informática em Saúde [Internet]. Brasília, DF: O Ministério; 2016 [acesso em 2020 jul. 20]. Disponível em: http://bvsms.saude.gov.br/bvs/ publicacoes/politica nacional infor informatica saude 2016.pdf. 